\title{
PENGARUH NEGATIVE FRAMING DAN ADVERSE SELECTION TERHADAP PENGAMBILAN KEPUTUSAN ESKALASI KOMITMEN (Studi Empiris pada Mahasiswa Akuntansi Universitas Malikussaleh)
}

\author{
Muhammad Yusra ${ }^{1}$, Surya Atika ${ }^{2}$ \\ ${ }^{1,2}$ Prodi Akuntansi Fakultas Ekonomi dan Bisnis Universitas Malikussaleh Lhokseumawe \\ myusra@unimal.ac.id
}

\begin{abstract}
This study aims to determine the effect of negative framing and adverse selection on commitment escalation decision making. The data used in this study are primary data. The population in this study are 178 active students majoring in Accounting of economics and business faculty, Malikussaleh University in 2014. The number of samples that met the research criteria were 64 students taken using a random sampling. The method used to analyze the relationship between the independent variable and the dependent variable is the technique of analyzing two ways ANNOVA using factorial $2 \times 2$ designs with instruments in the form of cases.The test results show that negative framing effect on commitment escalation, adverse selction effect on commitment escalation, and negative framing and adverse selection have no effect on commitment escalation.
\end{abstract}

Keywords: Negative Framing, Adverse Selection and eskalasi komitmen.

\section{PENDAHULUAN}

Manajer selaku pihak yang bertanggung jawab atas penggunaan modal perusahaan akan selalu menghadapi permasalahan penganggaran modal. Permasalahan ini timbul saat manajer diharuskan memilih sekumpulan pengeluaran modal yang harus dapat memuaskan dari segi keuangan dengan segala keterbatasan sumber daya yang ada. Pemilihan dan penggunaan teknik penganggaran modal yang tepat dapat membantu manajer untuk memilih usulan proyek investasi yang dapat memberi imbal hasil yang memuaskan. Manajer perlu melakukan analisis sejumlah faktor - faktor untuk dapat mengidentifikasi faktor utama pengambilan keputusan.

Menurut Soenhadji (2010) seorang pengambil keputusan haruslah memperhatikan hal-hal seperti logika, realita, rasional dan pragmatis. Meskipun banyak penelitian beranggapan bahwa pengambil keputusan adalah seorang yang rasional, namun, dalam praktek seringkali ditemukan beberapa penyimpangan dari asas rasionalitas tersebut. Tetapi, hasil dari riset perilaku akuntansi maupun psikologi menunjukkan bahwa para pembuat keputusan memiliki kecenderungan untuk melanjutkan suatu proyek yang sudah tidak ekonomis lagi. Contohnya, beberapa riset empiris menyatakan bahwa seringkali manajer mengambil keputusan untuk meneruskan suatu proyek yang mengalami kerugian yang terus menerus meskipun secara ekonomis proyek tersebut seharusnya dihentikan. Kondisi yang sering digambarkan sebagai "throwing good money after bad" hal ini disebut dengan eskalasi.

Ruchala dalam Ratih (2010) menyebutkan fenomena eskalasi sebagai keputusan untuk tetap melanjutkan proyek meskipun prospek ekonominya mengindikasikan bahwa proyek tersebut harus dihentikan. Eskalasi komitmen terjadi ketika individu maupun organisasi memilih serangkaian tindakan untuk tetap bertahan atau meninggalkan komitmen tersebut sama-sama memiliki ketidakpastian dalam konsekuensinya (Staw,1997 dalam Febri, 2015)

Seorang manager dalam mengambil keputusan seringkali mempunyai rasa ikatan emosional yang kuat dengan keputusan yang dibuat sebelumnya, sehingga manager tersebut mempunyai kesulitan dalam memisahkan keputusan yang diambil sebelumnya dengan keputusan yang berhubungan dengan masa depan (Bazerman dalam Tri Koroy Ramaraya, 2008 dalam sandi \& sukirno 2014 ). Hal ini membuat manajer cenderung membiaskan keputusannya sebagai akibat dari keputusan yang diambil sebelumnya dan mempunyai kecenderungan untuk meningkatkan komitmennya bila suatu informasi secara negatif diperoleh atas investasi yang telah dilakukan sebelumnya. 
Fenomena perilaku meningkatkan komitemen yang dilakukan manajer tersebut dapat dikatakan bahwa manajer tersebut telah melakukan suatu tindakan Eskalasi Komitmen. Dalam penelitian ini terdapat manajer yang tetap melanjutkan proyek investasinya walaupun proyek tersebut tidak menghasilkan laba yang signifikan atau dengan kata lain mengalami kegagalan.

Adapun rumusan masalah dalam penelitian ini adalah : 1.Apakah Negative Framing berpengaruh terhadap pengambilan keputusan Eskalasi Komitmen? 2. Apakah Adverse Selection berpengaruh terhadap pengambilan keputusan Eskalasi Komitmen? 3. Apakah Negative Framing dan Adverse Selection berpengaruh terhadap pengambilan keputusan Eskalasi Komitmen?

Sedangkan tujuan penelitian adalah :

1. Untuk mengetahui pengaruh Negative Framing terhadap pengambilan keputusan Eskalasi Komitmen. 2. Untuk mengetahui pengaruh Adverse Selectionterhadap pengambilan keputusan Eskalasi Komitmen. 3.Untuk mengetahui pengaruh Negative Framing dan Adverse Selection terhadap pengambilan keputusan Eskalasi Komitmen.

\section{TINJAUAN PUSTAKA}

\section{Teori Keagenan}

Teori keagenan (agency theory) memberi penjelasan mengenai eskalasi komitmen dengan memprediksi bahwa ketidakseimbangan informasi yang terjadi antara principle (pemilik) dengan agent (manager) akan mempengaruhi keputusan yang dibuat oleh manager tersebut. Salah satu masalah yang dapat ditimbulkan dari suatu ketidakseimbangan informasi adalah adverse selection (Sandi \& sukirno, 2014).

\section{Teori Prospek}

Teori prospek merupakan salah satu teoriyang mencoba menjelaskan pengaruh framing (Kahneman dan Tversky, 2017).Teori prospek (prospect theory) dari Kahneman dan Tversky (2017) menjelaskan terjdinya bias kognitif yang mempengaruhi pengambilan keputusan dalam kondisi ketidakpastian dan berisiko. Individu akan bersifat menghindari risiko atau menyukai risiko tergantung pada masalah yang dihadapi. Teori ini berpendapat bahwa individu akan memberikan bobot yang berlebihan terhdap hasil yang pasti dari pada yang belum pasti.

\section{ESKALASI KOMITMEN}

Eskalasi komitmen diartikan sebagai fenomena yang menjelaskan bahwa seseorang tetap meningkatkan atau menambah investasinya, meskipun adanya bukti yang menyatakan bahwa keputusan yang telah diambil keputusan yang salah.Eskalasi komitmen dalam penelitian ini diproksikan dengan keputusan manajeruntuk tetap melanjutkan proyek yang mengindikasikan kegagalan.

\section{NEGATIVE FRAMING}

Menurut Suartana (2005) framing adalah sebuah fenomena yang mengindikasikan pengambil keputusan akan memberi respon dengan cara berbeda pada masalah yang sama jika disajikan dalam format berbeda. Framing atas informasi dapat mempengaruhi seseorang dalam mengambil keputusan. Faktor lain yang mempengaruhi pengambilan keputusan pada seseorang adalah framing (Liang dkk, 2013 :3). Informasi yang dikatakan negative framing yaitu ketika informasi disajikan dalam bentuk pasti rugi, atau mengalami kegagalan.

\section{ADVERSE SELECTION}

Adverse selection, yaitu suatu keadaan dimana pemilik tidak dapat mengetahui apakah suatu keputusan yang diambil oleh manajer benar-benar didasarkan atas informasi yang telah diperolehnya atau terjadi kelalaian tugas (incentive to shirk). Atau terjadinya asimetri informasi yang terjadi antara kedua belah pihak.

\section{HUBUNGAN ANTAR VARIABEL Pengaruh negative framing Terhadap eskalasi komitmen}

Salter dan Sharp (2004) melakukan eksperimen dengan subjek yang digunakan adalah manajer AS dan Kanada, membuktikan bahwa negative framingdapat meningkatkan kemungkinan terjadinya eskalasi komitmen. Ketika hasil proyek sebagai suatu kerugian yang pasti (negative framing), manajer mempunyai kecenderungan risk taker yaitu tetap bertahan pada proyek tersebut. Dewanti (2010) menyatakan bahwa negative framing berpengaruh secarasignifikan terhadap eskalasi komitmen.

\section{$\mathrm{H}_{1} \quad$ : Negative Framing berpengaruh terhadap eskalasi komitmen}

\section{Pengaruh Adverse Selection Terhadap Eskalasi Komitmen}

Kondisi asimetri informasi yang terjadi antara manajer dengan pemilik perusahaan memberi kesempatan bagi manajer untuk melalaikan tugas (incentive to shirk) dimana manajer termotivasi untuk mencapai kepentingan yang bertentangan dengan pemilik. Kedua kondisi inilah merupakan awal terjadinya kondisi Adverse Selection Kondisi penguasaan informasi yang hanya dimiliki oleh manajer (informasi privat) dapat membuat manajer melakukan seleksi atas informasi yang akan disampaikan kepada pemilik, termasuk dalam hal ini adalah informasi performa proyek yang mulai memburuk dan juga terdapat kesempatan bagi manajer melalaikan tugas (incentive to shirk) untuk 
memenuhi kepentingan pribadi yang bertentangan dengan kepentingan pemilik, maka hal tersebut memberikan peluang bagi manajer untuk melakukan Eskalasi Komitmen.

Irfan, dkk (2013) menunjukkan manajer yang dihadapkan pada kondisi adverse selection mempunyai kecenderungan untuk melanjutkan proyek-proyek yang tidak menguntungkan. Selain itu Nurhayati dan Sukirno (2014) menyatakan bahwa adverse selection terbukti berpengaruh terhadap eskalasi komitmen.

\section{$\mathrm{H}_{2}$ : Adverse Selection berpengaruh terhadap eskalasi komitmen}

Pengaruh negative framing dan adverse selection Terhadap eskalasi komitmen

Suatu umpan balik yang diterima oleh manajer atas proyek ditanganinya maka manajer akan melihat kemungkinan untuk menghentikan atau melanjutkan proyek investasi tersebut. Peran kondisi adverse selection disini adalah ketika manajer tersebut memiliki informasi privat dan ada kesempatan untuk melalaikan tugas (incentive to shirk) bagi manajer tersebut, maka manajer tersebut akan cenderung mengejar kepentingannya sendiri dengan melanjutkan proyek yang tidak menguntungkan dan berharap mendapat pengambilan ppositif dimasa yang akan datang untuk memperbaiki kerugian diawal investasi proyeknnya.

Erlinda dan sukirno (2014 :9), maria dan milka (2012:221) menyatakan bahwa negative framing dan adverse selection secara bersama-sama berpengaruh terhadap eskalasi komitmen.

\section{$\mathrm{H}_{3}$ : Negative Framing dan Adverse Selection berpengaruh terhadap eskalasi komitmen}

\section{KERANGKA KONSEPTUAL}

Berikut ini disajikan kerangka pikir penelitian secara ilustratif mengenai Pengaruh negative framing dan adverse selection Terhadap pengambilan keputusan eskalasi komitmen sebagai berikut:

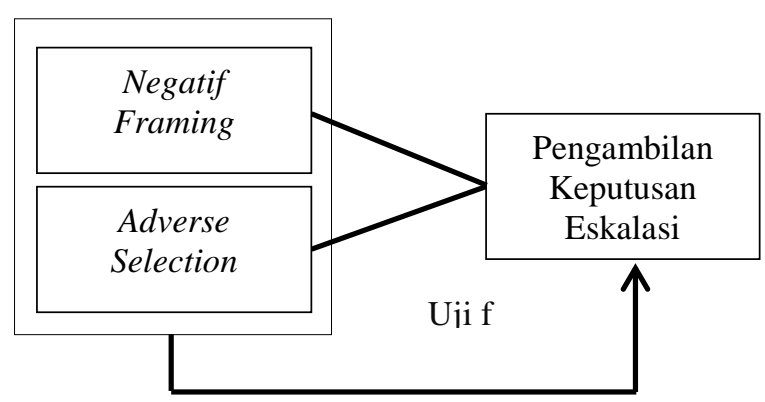

Gambar 1. Kerangka Penelitian

\section{METODE PENELITIAN}

Populasi dalam penelitian ini adalah Mahasiswa aktif Fakultas Ekonomi dan Bisnis Universitas Malikussaleh Program Studi Akuntansi Angkatan 2014 yang berjumlah 178 orang, yang telah mengambil mata kuliah Akuntansi Manajemen dan Manajemen Keuangan. Hal ini dikarenakan mahasiswa yang telah mengambil mata kuliah tersebut sudah memahami teori tentang pengambilan keputusan investasi sehingga dapat dijadikan Surrogate (pengganti manajer) dalam mengambil keputuan atas suatu proyek investasi.

Teknik pengambilan sampel dalam penelitian ini menggunakan metode random sampling. Random sampling adalah teknik pengambilan sampel dimana semua individu dalam populasi baik secara sendiri-sendiri atau bersama-sama diberi kesempatan yang sama untuk dipilih sebagao anggota sampel, Djarwanto (2000: 114).

Dalam mengukur sampel, peneliti menggunakan formula yang dikemukakan oleh Yamame, yaitu:

$n=\frac{\mathrm{N}}{\mathrm{N} \cdot \mathrm{d}^{2}+1}$

Dimana:

$\mathrm{n}=$ Jumlah sampel

$\mathrm{N}=$ Jumlah populasi

$\mathrm{d}=$ tingkat depresiasi yang diharapkan tidak menyimpang dari $10 \%$

Data yang digunakan dalam penelitian ini adalah data Primer. Data primer adalah sumber data yang diperoleh secara langsung dari sumber asli (tidak melalui perantara (Indriantoro, 2014).

Penelitian ini termasuk kedalam bentuk penelitian eksperimen.Penelitian ini menggunakan desain penelitian eksprimen factorial $2 \times 2$ (lihat tabel 3.1). faktor - faktornya terdiri dari dua variabel independen, yaitu negative framing dan adverse selection. Serta variabel dependen yaitu eskalasi komitmen.

Tabel 1 Desain penelitian $2 \times 2$ (negative framing $x$ adverse selection)

\begin{tabular}{|c|c|c|c|}
\hline \multicolumn{2}{|c|}{} & \multicolumn{2}{|c|}{ Adverse selection } \\
\cline { 3 - 4 } \multicolumn{2}{|c|}{} & Ada & Tidak ada \\
\hline $\begin{array}{l}\text { Negative } \\
\text { Framing }\end{array}$ & Ada & Kasus 1 & Kasus 3 \\
\cline { 2 - 4 } & Tidak ada & Kasus 2 & Kasus 4 \\
\hline
\end{tabular}

Sumber : Data Diolah Peneliti, 2018

\section{DEFENISI OPERASIONAL PENGUKURAN VARIABEL ESKALASI KOMITMEN (Y)}

Variabel dependen dalam penelitian ini adalah eskalasi komitmen yang mana kecenderungan menjadi over commitment terhadap serangkaian 
tindakan yang gagal sehingga tetap bertahan dengan tindakan tersebut dalam upaya memenuhi tujuan dimasa depan (Rahayu, 2010:149).

Pengukuran variabel eskalasi komitmen dalam instrumen dilakukan dengan melihat pilihan jawaban responden dalam skala Likert 1-6 (dimana $1=$ menghentikan proyek sampai dengan $6=$ melanjutkan proyek).

\section{NEGATIVE FRAMING $\left(\mathrm{X}_{1}\right)$}

Negative framing dalam penelitian ini disajikan dengan informasi mengenai kerugian yang pasti.

Pengukuran variabel framing negatif dalam instrumen dilakukan dengan dengan menggunakan skala Likert 1-6 dimana Skala 1 mencerminkan jawaban responden yang memilih untuk menghentikan proyek yang mengindikasikan kegagalan.dan Skala 6 mencerminkan jawaban responden (dalam hal ini responden merupakan surrogate dari manajer) yang memilih tetap melanjutkan proyek yang mengindikasikan kegagalan (eskalasi).

\section{ADVERSE SELECTION $\left(\mathrm{X}_{2}\right)$}

Adverse selection, yaitu suatu keadaan dimana pemilik tidak dapat mengetahui apakah suatu keputusan yang diambil oleh manajer benar-benar didasarkan atas informasi yang telah diperolehnya atau terjadi kelalaian tugas (incentive to shirk). Atau terjadinya asimetri informasi yang terjadi antara kedua belah pihak.

Pengukuran variabel adverse selection dalam instrumen dilakukan dengan dengan menggunakan skala Likert 1-6 dimana Skala 1 mencerminkan jawaban responden yang memilih untuk menghentikan proyek yang mengindikasikan kegagalan.dan Skala 6 mencerminkan jawaban responden (dalam hal ini responden merupakan surrogate dari manajer) yang memilih tetap melanjutkan proyek yang mengindikasikan kegagalan (eskalasi).

\section{HASIL PENELITIAN DAN PEMBAHASAN}

\section{Gambaran Umum Responden}

Penelitian ini dilakukan pada Mahasiswa S1 Fakultas Ekonomi dan Bisnis Universitas Malikussaleh Jurusan Akuntansi Angkatan tahun 2014, yang diproyeksikan sebagai manajer proyek. Salah satu tugas manajemen proyek yang berhubungan dalam penelitian ini adalah membuat keputusan untuk melanjutkan atau menghentikan proyek yang ditanganinya ketika mulai mengindikasikan prospek yang negatif.

Penelitian ini dilaksanakan melalui penyebaran kuesioner secara langsung, karena penelitian ini merupakan penelitian eksperimen, maka peneliti memantau secara langsung pengisian kuesioner tersebut. Penelitian ini dilakukan pada tanggal 18 februari - 21 februari 2018 di Fakultas Ekonomi dan Bisnis Universitas Malikussaleh.

Partisipan yang mengikuti penelitian ini berjumlah 64 partisipan, kuesioner yang disebarkan berjumlah 64 buah dan kuesioner yang kembali adalah sebanyak 64 kuesioner. Kuesioner yang dapat diolah berjumlah 60 , sedangkan kuesioner yang tidak dapat diolah karena tidak memenuhi kareteria sebagai sampel sebanyak 4 buah.

\section{HASIL UJI ASUMSI KLASIK Hasil Uji Normalitas}

Uji normalitas bertujuan untuk menguji apakah dalam suatu model regresi linear berganda variabel bebas dan variabel terikat keduanya mempunyai distribusi normal atau tidak. Pada uji ini digunakan teknik pengujian kolmogorofsmirnov. Uji kolmogorov-smirnov merupakan pengujian ststistis non-parametric yang paling mendar dan paling banyak digunakan, uji ini digunakan untuk menguji "goodness of fit" antar distribusi sampel dan distibusi lainnya.

Tabel 2

One-Sample Kolmogorov-Smirnov Test

\begin{tabular}{|cc|c|}
\hline & & $\begin{array}{c}\text { Unstandardi } \\
\text { zed Residual }\end{array}$ \\
\hline $\mathrm{N}$ & & 60 \\
Normal $^{a}, b$ & Mean &, 0000 \\
Parameters & Std. &, 97424 \\
& Deviation & \\
Most & Absolute &, 140 \\
Extreme & Positive &, 140 \\
Differences & Negative &,- 105 \\
Test Statistic & & 1.084 \\
Asymp. Sig. (2-tailed) &, 191 \\
\hline
\end{tabular}

Sumber : Hassil Penelitian, 2018

Berdasarkan tabel 2. one-sample kolmogorovsmirnov test, menunjukkan bahwa nilai asymp. Sig. (2-tailed) $>0,05$ maka data berdistribusi normal.

\section{Uji Homogenitas}

Uji homogenitas digunakan untuk mengetahui apakah varian populasi sama atau tidak. Uji homogenitas dilakukan sebagai uji prasyarat sebelum melakukan uji analysis of variance. Sebagai kriteria pengujian homogenitas, jika nilai signifikansi lebih dari 0,05 maka dapat dikatakan bahwa varian dari dua atau lebih kelompok data adalah homogen (Gendro Wiyono, 2011 : 152).

Tabel 3 Uji Homogenitas

\begin{tabular}{|c|c|c|c|}
\hline$F$ & df1 & $\mathrm{df} 2$ & Sig. \\
\hline .229 & 3 & 56 & .875 \\
\hline
\end{tabular}

Sumber: Hasil Penelitian, 2018 
Dari tabel diatas, dapat diketahui nilai signifikansi sebesar 0,875 lebih besar dari 0,05, Maka dapat dikatakan bahwa varian dari dua atau lebih kelompok data adalah homogen. Dapat disimpulkan asumsi homogenitas varians yang merupakan asumsi prasyarat analisis varians terpenuhi, dan dapat dilanjutkan ke uji anova.

\section{HASIL PENGUJIAN HIPOTESIS Hasil Two Way Anova}

Analisis of variance digunakan untuk menganalisis variabel yang berupa nilai atau angka dengan beberapa asumsi yang mendasarinya untuk membandingkan rata-rata kelompok yang ada. Tujuan utama penggunaan annova adalah untuk menganalisis perbedaan yang ada dari berbagai kelompok terhadap satu faktor yang akan menjadi interest factor (Efferin, dkk, 2004).

Teknik analisis data yang digunakan untuk menguji hipotesis pada penelitian ini menggunakan model two ways anova. Two ways anova digunakan untuk menguji dua variabel independen dengan dua kategori.

Uji two ways anova dalam penelitian ini dilakukan dangan bantuan program spss dan hasil pengujiannya dapat dilihat pada tabel berikut:

Tabel 4.8 Uji Two way Annova

\begin{tabular}{|l|c|c|c|}
\hline \multicolumn{1}{|c|}{ Variabel } & $\mathrm{F}$ & Sig & Keterangan \\
\hline Negative Framing & 4.131 & .047 & H1 Diterima \\
\hline Adverse Selection & 4.131 & .047 & H2 Diterima \\
\hline $\begin{array}{l}\text { NegativeFraming* } \\
\text { Adverse Selection }\end{array}$ & .115 & .736 & H3 Ditolak \\
\hline \multicolumn{4}{|l|}{ Dependen Variabel : Eskalasi Komitmen } \\
\hline
\end{tabular}

Sumber: Hasil Penelitian, 2018

\section{$\mathrm{H}_{1} \quad$ : Negative Framing berpengaruh terhadap eskalasi komitmen}

Hipotesis 1 yaitu negative framing berpengaruh terhadap eskalasi komitmen. F hitung untuk variabel X1 (Negative Framing) adalah 4,131 dan nilai signifikansi 0,047. Sedangkan untuk Ftabel dengan taraf signifikansi $5 \%$ serta df pembilang 1 dan df penyebut 56diperoleh nilai Ftabel $=4,01$. Karena Fhitung $\geq$ Ftabel yaitu 4,131 $\geq 4$,01dan nilai signifikansi $\leq 0,05$ yaitu $0,047 \leq 0,05$, H1 diterima.

Hasil ini mampu membuktikan bahwa, ketika manajer menerima informasi yang di-framing secara negatif dalam bentuk pilihan antara kerugian pasti yang telah terjadi dengan kerugian dimasa mendatang yang belum pasti dari proyek investasi yang sedang ditanganinya, maka manejer tersebut cenderung lebih meningkatkan komitmenya dengan membuat keputusan melanjutkan proyek investasi yang tidak mengguntungkan (eskalasi komitmen). Dengan memilih melanjutkan proyek, manajer memilih menambahkan dana berharap mendapat pengembalian yang positif dimasa mendatang.

Hasil penelitian ini mendukung hasil penelitian Dian Lestari (2015) yang menyatakan bahwa terdapat pengaruh signifikan dari negative framing terhadap eskalasi komitmen dalam suatu kasus pengambilan keputusan investasi proyek yang tidak mengguntungkan.

\section{$\mathrm{H}_{2}$ : adverse selection berpengaruh terhadap eskalasi komitmen.}

Hipotesis 2 yaitu adverse selection berpengaruh terhadap eskalasi komitmen. F hitung untuk variabel X2 (Adverse Selection) adalah 4,131 dan nilai signifikansi 0,047. Sedangkan untuk Ftabel dengan taraf signifikansi $5 \%$ serta df pembilang 1 dan df penyebut 56diperoleh nilai Ftabel $=4,01$. Karena Fhitung $\geq$ Ftabel yaitu 4,131 $\geq 4$,01dan nilai signifikansi $\leq 0,05$ yaitu $0,047 \leq 0,05$, H2diterima

Hasil pengujian tersebut mampu membuktikan bahwa, seorang manajer yang memiliki informasi privat yang tidak diketahui orang lain dalam perusahaan ditambah dengan terdapat kesempatan untuk melalaikan tugas (incentive to shirk) bagi manajer (kondisi adverse selection), maka keputusan yang dibuat manajer cenderung melanjutkan proyek investasi yang tidak menguntungkan.

Hasil penelitian ini juga mendukung atau sesuai dengan penelitian sebelumnya yang dilakukan oleh Muhammad Sandi Arimawan (2014), Dian lestari (2015), yang menyatakan bahwa, terdapat pengaruh antara adverse selection terhadap eskalasi komitmen.

\section{$\mathrm{H}_{3} \quad$ : negative framing dan adverse selection berpengaruh terhadap eskalasi komitmen}

Hipotesis 3 yaitu negative framing danadverse selection tidak berpengaruh terhadap eskalasi komitmen. F hitung untuk variabel X1 * X2 (Interaksi Negative Framing dan Adverse Selection) adalah 0,115 dan nilai signifikansi 0,736. Sedangkan untuk F tabel dengan taraf signifikansi $5 \%$ serta df pembilang 1 dan df penyebut 56diperoleh nilai Ftabel $=4,01$. Karena Fhitung $<$ Ftabel yaitu $0,115 \geq 4,01$ dan nilai signifikansi $>0,05$ yaitu $0,736>0,05, \mathrm{H} 3$ ditolak.

Hal tersebut mungkin saja terjadi ketika manajer memiliki pandangan bahwa kesuksesan ornigasasi erat hubungannya dengan kepuasan prinsipal. Manajer akan lebih kooperatif kerena menganggap bahwa terdapat utilitas yang lebih besar pada prilaku kooperatif terhadap kepentingan perusahaan. Dengan demikian, meskipun memiliki 
kesempatan untuk melalaikan tugas maupun memiliki informasi privat tentang prospek suatu proyek yang mengindikasikan kegagalan, manajer tetap mengutamakan kepentingan perusahaan dengan tidak mengeskalasi komitmennya.Hasil penelitian ini mendukung hasil penelitian yang dilakukan oleh Dewanti (2010) dan Dwita (2007) yang membuktikan bahwa tidak terdapat pengaruh interaksi antara negative framing dengan adverse selection terhadap eskalasi komitmen. Hal ini menunjukan bahwa responden dalam penelitian ini pada dasarnya bersifat risk averse atau cenderung menghindari risiko.

\section{SIMPULAN DAN SARAN}

\section{Simpulan}

Berdasarkan Penelitian ini bertujuan untuk mengetahui pengaruh negative framing dan adverse selection terhadap pengaruh eskalasi komitmen. Berdasarkan pada data yang telah dikumpulkan dan pengujian yang telah dilakukan terhadap permasalahan dengan menggunakan simple faktorial ANOVA (two way anova), maka dapat diambil kesimpulan sebagai berikut :

1. Negative framing berpengaruh terhadap keputusan eskalasi komitmen. Hasil pengujian mendukung $\mathrm{H}_{1}$ bahwa ketika informasi disajikan dalam bentuk framing negatif. Dapat disimpulkan bahwa, pengambil keputusan cenderung akan melanjutkan proyek yang mengindikasikan kegagalan.

2. Adverse selection berpengaruh terhadap eskalasi komitmen. Hasil pengujian mendukung $\mathrm{H}_{2}$ bahwa manajer yang mendapat perlakuan adverse selection akan cenderung melanjutkan proyek investasi yang mengindikasikan kegagalan ( eskalasi komitmen tinggi) dari pada manajer yang tidak mendapat perlakuan adverse selection.

3. Negative framing dan adverse selection tidak berpengaruh secara bersama-sama terhadap eskalasi komitmen. Berdasarkan hasil tersebut, dapat disimpulkan bahwa Hasil tersebut menunjukkan manajer yang mendapat perlakuan negative framing dan adverse selection cenderung menghentikan proyek investasi yang mengindikasikan kegagalan (eskalasi komitmen rendah) dari pada manajer yang mendapat perlakuan tanpa negative framing dan adverse selection.

\section{Saran}

Berdasarkan hasil pembahasan dan kesimpulan diatas maka saran yang dapat dikemukakan sebagai berikut:
1. Mahasiswa sebagai calon manajer dimasa depan, dapat menyikapi fenomena eskalasi komitmen dalam pengambilan keputusan dengan bijak, dimana tindakan eskalasi komitmen dapat merugikan diri sendiri dan perusahaan.

2. Penelitian selanjutnya diharapkan menggunakan partisipan manajer sesungguhnya bukan subjek mahasiswa, karna apabila menggunakan subjek mahasiswa kemungkinan terjadi bias penelitian sangatlah besar.

\section{DAFTAR PUSTAKA}

Dewanti, Ratih, (2010). Pengaruh Negative Framing dan Job Rotation pada Kondisi Adverse Selection terhadap Pengambilan Keputusan Eskalasi Komitmen (skripsi).Semarang:

Universitas Diponegoro.

Dwita, Sany, (2007). Influnce of Adverse Selection and Negative Framing on Esclation of Commitment In Project Evaluation Decisions. Simposium Nasional Akuntansi X. Makassar.

Eveline, F, (2010). Pengaruh Adverse Selection, Pembingkaian Negatif, dan Self Efficacy terhadap Eskalasi Komitmen Proyek Investasi yang Tidak Mengguntungkan. Jurnal Akuntansi \& Management, Vol. 21, No. 2, Agustus 2010, hal. 181-198.

Helmayunita, N (2015). Pengaruh Adverse Selection, Kontrol Monitoring Dan Penalaran Moral Individu Terhadap Perilaku Eskalasi Komitmen. Program Studi Akuntansi Fakultas Ekonomi UNP.

Ikhsan, Arfan dan Muhammad Ishak. "Akuntansi Keperilakuan”, Selemba Empat. Jakarta ,2005.

Kahneman D, Tversky a.(2017). "choices, values, frames". Cambridge (uk): Cambridge University Press

Kelly dan Milkman KL. (2013). Encyclopedia of management theory. Kessler eh, editor. Thousand oaks (CA):sage publications.

Koroy , T, R, (2008). Pengujian Efek Pembingkaian Sebagai Determinan EskalasiKomitmen Dalam Keputusan Investasi: Dampak Dari Pengalaman Kerja. Simposium Nasional Akuntansi $X I$. Pontianak. 
Kusuma, Erlinda Wardani, (2014). Pengaruh Framing Effect terhadap pengambilan keputusan investasi dengan locus of control sebagai variabel pemoderasi. Jurnal Nominal Vol. 1. Hal. 56 - 60.

Kreitner, Robert \& Kinicki, Angelo. (2005). Perilaku Organisasi. Edisi 5. (Alih bahasa: Erly Suandy). Jakarta: Salemba Empat.

Maria, dan Milka, (2012). Pengaruh adverse selection dan negative framing terhadap eskalasi komitmen. EcoEnterpreneurship Seminar \& Call for Paper Improving Performance by Improving Environment. Fakultas Ekonomi. Universitas Negeri Semarang.

Nurhayati, F. dan Sukirno (2014). Pengaruh Adverse Selectiondan Kompensasi terhadap Eskalasi Komitmen. Jurnal Prifita: Kajian Ilmu Akuntansi, Vol 2, No.4.

Salter, S. B. Dan D.J. Sharp. (2004). The Determinants of Escalation Commitment : National Culture And Experience Effects. University Of Cincinnati. (Http:/www.Ebscohost.Com). (Accessed Juli 2011)

Sandi,\& Sukirno (2014). Pengaruh Negative Framing dan Adverse Selection terhadap Eskalasi Komitmen. Jurnal Nominal Vol. 3. No. 1.

Santoso, A.B. (2012). Peranan Locus Of Control, Self-Set Dan Organizational-Set Hurdle Rates Terhadap Eskalasi Komitmen Pada Level Pengambilan Keputusan Pengaggaran Modal. Jurnal ilmiah mahasiswa akuntansi. Vol.1 No.3,mei 2012

Sari \& Wirakusuma (2017).Pengaruh Aadverse Selection Dan Negative Framing Pada Kecenderungan Eskalasi Komitmen. Fakultas Ekonomi Dan Bisnis Universitas Undayana Bali Indonesia.

Soehandji, I, M, (2010). Teori Pengambilan Keputusan. Power Point Presentation. Universitas Gunadarma.

Sugiyono.(2010).Metode Penelitian Kuantitatif Kualitatif Dan $\quad \mathbf{R} \quad \boldsymbol{\&} \quad \mathbf{D}$ Penerbit Alfabeta.Bandung.

Yahya dan Surya. Pengaruh Framing Effect Sebagai Determinan Escalation of
Comitment Dalam Keputusan Investasi : Dampak Dari Working Experiences, Jurnal Akuntansi, Vol.4, No.2, Hal.153-164, 2012 
